\title{
Effects of a single bout of walking on psychophysiologic responses and executive function in elderly adults: a pilot study
}

This article was published in the following Dove Press journal:

Clinical Interventions in Aging

18 July 2013

Number of times this article has been viewed

\author{
Arihiro Hatta' \\ Yoshiaki Nishihira ${ }^{2}$ \\ Takuro Higashiura ${ }^{3}$ \\ 'Department of Health Pharmacy, \\ Yokohama College of Pharmacy, \\ Yokohama, Kanagawa, Japan; \\ ${ }^{2}$ Graduate School of Comprehensive \\ Human Sciences, University of \\ Tsukuba, Tsukuba, Ibaraki, Japan; \\ ${ }^{3}$ Department of Law, Faculty of Law, \\ Seiwa University, Kisarazu, Chiba, \\ Japan
}

Background: The purpose of this study was to examine the effects of a single bout of walking on mood, psychophysiologic responses, and executive function in elderly adults.

Methods: Twenty healthy, elderly adults (10 women and 10 men; mean age $70.50 \pm 3.4$ years) participated in this study. Mood, as assessed by the Profile of Mood States, and salivary $\alpha$-amylase activity were examined before and after walking. Executive functions were also evaluated by the Wisconsin Card Sorting Test.

Results: Negative feeling scores such as tension-anxiety, anger-hostility, and confusion significantly improved after walking. No significant differences were found for either salivary $\alpha$-amylase activities or Wisconsin Card Sorting Test scores before and after walking. However, the changes in salivary $\alpha$-amylase activity before and after walking correlated positively with the number of total errors and perseverative errors of Nelson in the Wisconsin Card Sorting Test.

Conclusion: These results suggest that moderate exercise, such as self-paced one-time walking, induces beneficial psychologic effects in elderly adults. Meanwhile, the significant increase in salivary $\alpha$-amylase activity after walking might temporarily cause deterioration of executive function.

Keywords: salivary $\alpha$-amylase, Profile of Mood States, Wisconsin Card Sorting Test, perseverative error

\section{Introduction}

Aging is a gradual process of morphologic and physiologic changes that naturally predisposes older adults to progressive weakening, functional decline, morbidity, disability, poor quality of life, and increased mortality. ${ }^{1}$ The "super-aging society" is a critical concern, and the average period of caregiving for cognitively impaired patients is said to be about 6-7 years in Japan; therefore, not only shortening the caregiving duration but also extending the healthy life expectancy is an important issue.

Physical exercise improves the efficiency of the capillary system and increases the oxygen supply to the brain, thus enhancing metabolic activity and oxygen intake in neurons, and increases neurotrophin levels and resistance to stress. ${ }^{2}$ Regular exercise and an active lifestyle during adulthood have been associated with a reduced risk of, and protective effects against, mild cognitive impairment and Alzheimer's disease. ${ }^{2}$ Electroencephalography has shown that physically active older adults are able to recruit more brain resources to improve performance on various cognitive and motor tasks than their sedentary counterparts. ${ }^{3,4}$ Further, improvements in cognitive function as a result of exercise and physical training have also been widely demonstrated with benefits for executive function. ${ }^{5-7}$
Correspondence: Arihiro Hatta

Department of Health Pharmacy,

Yokohama College of Pharmacy,

610 Matanocho, Totsuka, Yokohama,

Kanagawa 245-0066, Japan

Tel $+8 \mid 45859$ I 300

Fax $+8 \mid 458528178$

Email a.hatta@hamayaku.ac.jp 
Executive function consists of a number of processes, including monitoring and control of behavior, suppression of irrelevant information, reasoning, updating information in working memory, inhibition of prepotent responses, planning, shifting, and control of attention. ${ }^{8}$ Daily activities requiring active problem-solving, efficient organization strategies, working memory, and regulation of behavior rely on efficient executive function. Improving the cognitive deficits associated with executive function may therefore have an important impact on quality of life. ${ }^{9}$

Physiologic stress responses are also important determinants of health and disease. ${ }^{10}$ The consequences of stress can be both harmful and beneficial, depending on the intensity, duration, and frequency of the stress, and on the price paid in terms of energy utilization and other metabolic disturbances. ${ }^{11}$ Two main body systems are involved in the stress response, ie, the autonomic nervous system and the hypothalamic-pituitary-adrenal axis. Cortisol is secreted from the adrenal cortex via the hypothalamic-pituitary-adrenal axis and increases in response to stressors including physical exertion. ${ }^{12,13}$ Cortisol and catecholamines have been found to be reliable indicators of the reactivity of the physiologic stress system.

Salivary $\alpha$-amylase has also been proposed as a biomarker of body stress and sympathetic nervous system activity. ${ }^{14}$ Significant increases of salivary $\alpha$-amylase were found after more intense and/or longer bouts of exercise, such as running a marathon.${ }^{15}$ Chatterton et $\mathrm{al}^{16}$ found a significant positive correlation between salivary $\alpha$-amylase and plasma norepinephrine in the response to exercise, and showed a dose-response effect with highest salivary $\alpha$-amylase increases after running as compared with light jogging and walking. Moreover, salivary $\alpha$-amylase activity has been reported to be a more sensitive marker of psychologic stress ${ }^{17}$ and exercise-induced stress than cortisol. ${ }^{18}$ It is thought that salivary $\alpha$-amylase measurement will be a powerful tool for psychologic research ${ }^{17}$ and may be a useful index for evaluating psychophysiologic stress before and after exercise. ${ }^{19}$

Meanwhile, exercise and physical activity reduce mood disturbances such as depression, regardless of the amounts of physical activity in older adults. ${ }^{20}$ Recent studies have also found that physical activity may both reduce negative affect and increase positive affect on the Profile of Mood States..$^{21,22}$ In particular, walking is one of the most popular exercises irrespective of age or sex, and is governed by a complex motor control system comprising somatosensory, visual, and vestibular elements that interact with spinal, supraspinal, and peripheral motor circuitry. ${ }^{23}$ Moreover, walking is deemed to promote motivation and to be generally safe, is most likely to be an adequate form of physical exercise for the elderly, ${ }^{24}$ and is also beneficial for cognitive function in those with mild to moderate Alzheimer's disease. ${ }^{25}$ Accordingly, walking is expected to have both physiologically and psychologically beneficial effects and is considered to be a health-improving or life-prolonging exercise.

However, exercise can induce several stresses in the host, including eustress and distress, which may have both positive and negative effects. ${ }^{26}$ It remains uncertain how exercise modulates psychophysiologic stress responses in elderly adults. The association between psychophysiologic stress and executive function also remains unclear. The hypothesis behind the present study was that transient moderate exercise exerts beneficial influences, resulting in improvement of mood, psychophysiologic responses, and executive function. We examined the effects of a single bout of walking on psychophysiologic responses and executive functions in elderly adults.

\section{Materials and methods \\ Participants}

Twenty healthy, Japanese, elderly adults (10 women and 10 men, mean age $70.50 \pm 3.4$ years) participated in this study. Table 1 shows the demographic characteristics of participants. Participants gave their written informed consent before participating in the study after the purpose and procedure had been fully explained to them, and they were free from neurologic or psychiatric disorders.

\section{Procedure}

Subjective psychologic stress responses were assessed using the 30-item Profile of Mood States-(brief Japanese version) (POMS), and salivary $\alpha$-amylase activity was measured using the psychophysiologic measure immediately before and after walking. Executive function was evaluated by the Keio version of the Wisconsin Card Sorting Test (WCST) immediately before and after walking. To minimize the potential effects of circadian rhythmicity on the measured biological parameters,

Table I Demographic characteristics of participants (means \pm standard deviation)

\begin{tabular}{lcc}
\hline & Men $(\mathbf{n}=1 \mathbf{0})$ & Women $(\mathbf{n}=1 \mathbf{0})$ \\
\hline Age (years) & $71.70 \pm 3.2$ & $69.3 \pm 3.2$ \\
Body height $(\mathrm{cm})$ & $166.80 \pm 5.2$ & $156.30 \pm 2.7$ \\
Body weight $(\mathrm{kg})$ & $63.30 \pm 8.4$ & $52.98 \pm 8.3$ \\
BMI $\left(\mathrm{kg} / \mathrm{m}^{2}\right)$ & $22.72 \pm 2.7$ & $21.84 \pm 3.1$ \\
\hline
\end{tabular}

Abbreviation: BMI, body mass index. 
all measurements were scheduled at the same time in the morning between 9 am and noon. The experimental room was air-conditioned at $24^{\circ} \mathrm{C}$. The ethical committee of the University of Tsukuba approved the experimental protocol.

Each participant undertook 80-120 minutes of self-paced walk (no fixed distance) in order to achieve approximately $7,000-10,000$ steps in one walk, the recommendation for healthy older adults to maintain and/or improve their health. ${ }^{27-29}$ Participants were instructed to walk at their own pace that was fairly light, and not to walk too fast. Participants could also rest to drink water whenever they felt tired. Participants wore a pedometer (HJ-710IT, Omron Co, Kyoto, Japan) to measure the number of steps walked. Heart rate (HR) at rest and during walking was recorded by HR monitoring equipment (RS100; Polar Electro, Kempele, Finland). Exercise intensity was expressed as the percent of maximal HR (\% $\mathrm{HR}_{\text {max }}$ ), estimated by dividing each participant's actual HR by their age-predicted maximum HR (220 - age in years).

\section{Profile of Mood States}

Mood states were measured immediately before and after walking using the POMS. Participants rated the intensity of 30 mood items on a five-point Likert-type scale ranging from "not at all" to "extremely" (0-4). Participants were asked to respond as to how they felt "right now". These raw scores were added up to categorize six subscales, ie, tension-anxiety, depression, anger-hostility, vigor, fatigue, and confusion.

\section{Salivary $\alpha$-amylase}

Salivary $\alpha$-amylase activities were measured immediately before and after walking. Participants were instructed not to eat or drink (except water) for 30 minutes prior to saliva collection and to rinse their mouth with clear water immediately before each collection. We used a hand-held monitor (CM-2.1, Nipro Corporation, Osaka, Japan) and reagent paper to measure enzymatic salivary $\alpha$-amylase activity. This measurement method can be performed easily and quickly and is a convenient and useful objective indicator in medical and educational practice. The salivary $\alpha$-amylase biosensor consists of disposable colorimetric test strips and a hand-held reader that utilizes a miniaturized optical platform to detect and quantify salivary $\alpha$-amylase rapidly. Inputted algorithms normalize variations in ambient temperature and salivary $\mathrm{pH}$. The small test strip is placed under the tongue for 15 seconds and then removed and inserted into the sensor unit. The biosensor provides a readout of salivary $\alpha$-amylase activity within approximately 15 seconds. ${ }^{30}$ This analysis method has been used by various researchers ${ }^{30-32}$ and has accuracy, precision and measurement reliability that approach a sophisticated laboratory-based analyzer. ${ }^{32}$

\section{Wisconsin Card Sorting Test}

The WCST was administered to all participants using a computerized Keio version, a modification of the original standardized and validated version. The WCST was chosen because of its good construct validity for older adults and because it did not require high levels of instruction for participants in this study.

The participants sat on a comfortable chair in a quiet room with their eyes on the computer screen on which the WCST was displayed and were asked to perform one series of the WCST (48 cards). The participants were instructed to match a response card to one of the four stimulus cards on the basis of one of the three possible categories of number, color, or shape, by clicking one of the stimulus cards using a mouse. The participants were required to determine the correct sorting category based solely on feedback from the display indicating "correct" or "wrong". When the subjects maintained correct responses consecutively for six trials, the category was changed without warning and they had to shift the sorting rule from the previously relevant category to another to yield correct answers.

Performance on the WCST was evaluated based on the number of completed categories (CA), total errors (TE), and perseverative errors of Nelson (PEN). The CA refers to the capacity for abstraction, which is the ability to concentrate on the essential aspects of a specific context and ignore other aspects present that have incidental or less relevance. Perseverative errors refer to an individual's mental flexibility, that is, the capacity to respond to contingencies, by inhibiting an inappropriate response and seeking an appropriate response. ${ }^{33}$

\section{Statistical analysis}

Data were analyzed using Super analysis of variance (ANOVA) software (Abacus Concepts Inc., Berkeley, CA, USA). Six subscales for POMS were converted to a T-score and these scores were normalized for sex and age. Repeated measures analysis of variance was performed on the POMS for the following variables: exercise (before walking, after walking) $\times$ subscales (tension-anxiety, depression, anger-hostility, vigor, fatigue, and confusion). Repeated measures analysis of variance was also performed on salivary $\alpha$-amylase activities for the following variables: exercise (before walking, after walking) and on the WCST for the following variables: exercise (before walking, 
after walking) $\times$ categories $(\mathrm{CA}, \mathrm{TE}, \mathrm{PEN})$. To decrease the experiment-wise error rate due to the repeated measures design involving multiple dependent variables, Greenhouse-Geisser adjustment of the degrees of freedom was performed. This correction was applied when the violations of sphericity for significant effects occurred in the analysis of variance with two or more degrees of freedom. Post hoc testing (contrast) was conducted only when preceded by significant analysis of variance effects.

In addition, correlation analyses were conducted between changes in salivary $\alpha$-amylase activity ( $\triangle \mathrm{SAA})$ and those in WCST scores ( $\triangle \mathrm{CA}, \triangle \mathrm{TE}$, and $\triangle \mathrm{PEN})$, before and after walking, were examined by determination of Spearman's rank correlation coefficient. Data analyses were conducted with StatView 4.5 (Abacus Concepts Inc.). Changes in salivary $\alpha$-amylase and WCST scores were calculated using the following formulas: pre-salivary $\alpha$-amylase activities $(\mathrm{kU} / \mathrm{L})$ - post-salivary $\alpha$-amylase activities $(\mathrm{kU} / \mathrm{L})$ and pre-WCST score - post-WCST score, respectively. Statistical significance was set at $P<0.05$.

\section{Results}

The mean HR during walking was $101.00 \pm 11.1$ beats per minute, corresponding to $67.40 \% \pm 8.0 \% \mathrm{HR}_{\max }$. The mean duration of walking and the number of steps were $105.20 \pm 18.9$ minutes and 9,629.35 $\pm 1,835.4$ steps, respectively.

Regarding mood states, both exercise and subscales showed significant main effects. There were also significant interactions between exercise and subscales $(F=3.54$, $P<0.01)$. Post hoc tests showed that negative feeling scores for tension-anxiety, anger-hostility, and confusion were significantly lower after walking than before walking $(F=18.056, P<0.001 ; F=7.855, P<0.05$; and $F=13.078$, $P<0.01$, respectively, Table 2).

Contrary to our hypothesis, there was no significant main effect of exercise on salivary $\alpha$-amylase $(F=0.023$, $P=0.881$, Table 3 ). The salivary $\alpha$-amylase activity of 13 participants increased after walking, and that of seven participants decreased after walking. There was no correlation between salivary $\alpha$-amylase activity and exercise duration and/or number of steps.
Regarding executive function, there was no significant main effect of exercise $(F=1.749, P=0.2017)$ and no significant interactions between exercise and categories $(F=2.263$, $P=0.144$, Table 3 ). There were no correlations between salivary $\alpha$-amylase activity and WCST scores. However, positive correlations were found between $\triangle \mathrm{sAA}$ and WCST scores ( $\Delta \mathrm{TE}, \rho=0.516, P<0.05$ [Figure 1] and $\Delta \mathrm{PEN}, \rho=0.650$, $P<0.01$ [Figure 2]) before and after walking.

\section{Discussion}

The objective of this study was to examine the effects of a single bout of walking on psychophysiologic responses and executive function in healthy elderly adults. The mood results in the present study showed improvements in tension-anxiety, anger-hostility, and confusion scores after self-paced walking. Schneider et a ${ }^{34}$ showed that positive psychologic results after exercise can be more significant when self-selected exercise intensities are used. The beneficial effects of exercise on mental and mood aspects in the elderly have been reported in several studies. ${ }^{20,35}$ Their findings are in line with the results of the present study. Confusion scores improved significantly after walking, suggesting that moderate aerobic exercise such as self-paced walking exerts a beneficial influence on brain function (ie, feeling clear-headed). Further research is needed to examine the effects of walking on healthy brain aging (ie, delay in onset of cognitive decline).

Salivary $\alpha$-amylase has been used as a possible biomarker of autonomic nervous system reactivity to stress. ${ }^{19,36}$ Chatterton et $\mathrm{al}^{16}$ reported increased salivary $\alpha$-amylase, epinephrine, and norepinephrine concentrations after aerobic exercise. Moreover, de Oliveira et $\mathrm{al}^{37}$ found acute increases in salivary $\alpha$-amylase levels following incremental cycling, and a strong relationship between salivary $\alpha$-amylase and blood lactate concentrations was evident. Thus, salivary $\alpha$-amylase activity increased in response to acute exercise and the magnitude of the increase was mostly dependent on exercise intensity. ${ }^{14}$ However, there was no significant difference in salivary $\alpha$-amylase activity before and after walking in the present study. We assume that these results were because exercise intensity, including exercise duration and steps, was not the same for each participant because of

Table 2 Mood measurements (means \pm standard deviation) for POMS before and after walking

\begin{tabular}{lllllll}
\hline & TA & D & AH & V & F & C \\
\hline Before walking & $46.45 \pm 8.5$ & $46.45 \pm 6.2$ & $44.35 \pm 6.5$ & $49.65 \pm 8.0$ & $43.65 \pm 7.0$ & $50.15 \pm 8.8$ \\
After walking & $41.75 \pm 6.2 * * *$ & $44.50 \pm 5.1$ & $41.25 \pm 4.7^{*}$ & $50.65 \pm 10.9$ & $42.55 \pm 4.8$ & $46.15 \pm 6.6 * *$ \\
\hline
\end{tabular}

Notes: A significant difference between before and after walking; $* P<0.05$, $* * P<0.01$, $* * * P<0.001$.

Abbreviations: POMS, profile of mood states; TA, tension-anxiety; D, depression; $\mathrm{AH}$, anger-hostility; $\mathrm{V}$, vigor; $\mathrm{F}$, fatigue; $\mathrm{C}$, confusion. 
Table 3 sAA activities and WCST scores (means \pm standard deviation) before and after walking

\begin{tabular}{lllll}
\hline & sAA (kU/I) & \multicolumn{2}{l}{ WCST } \\
\cline { 3 - 5 } & & CA & TE & PEN \\
\hline Before walking & $90.80 \pm 89.3$ & $4.20 \pm 1.4$ & $17.15 \pm 6.1$ & $4.00 \pm 3.0$ \\
After walking & $93.60 \pm 50.9$ & $4.80 \pm 1.4$ & $14.30 \pm 4.9$ & $3.25 \pm 3.2$ \\
\hline
\end{tabular}

Abbreviations: sAA, salivary $\alpha$-amylase; WCST, Wisconsin Card Sorting Test; CA, category achievement; TE, total errors; PEN, perseverative errors of Nelson.

self-paced walking in this study. Some participants showed an increase in salivary $\alpha$-amylase activity after walking while others showed a decrease. Strahler et a ${ }^{38}$ speculated that regular physical activity could reduce sympathetic and hypothalamic-pituitary-adrenal axis hyperactivity in older adults, as indicated by lower overall salivary $\alpha$-amylase activity and cortisol output in more active subjects. Further studies will be needed to investigate the effect of regular physical activity or the actual fitness level of participants on salivary $\alpha$-amylase activity. Meanwhile, it is possible that a subjective feeling of fatigue after exercise does not necessarily accord with physical fatigue in this study. Therefore, salivary $\alpha$-amylase activity may be a useful, noninvasive fatigue index to evaluate psychophysiologic stress responses before and after exercise in elderly people.

Most daily tasks are performed almost automatically, but occasionally it is necessary to alter a routine if something changes in the environment and routine behavior becomes inappropriate. ${ }^{39}$ Cognitive flexibility to select appropriate rules in a changing environment is essential for survival and is assumed to depend on the integrity of the prefrontal cortex. Cognitive flexibility in rule-switching tasks such as the WCST relies on the interplay of multiple cognitive processes, and impairment in any one of them might lead to a performance deficit. ${ }^{40}$ In the present study, there was no significant main effect of exercise on WCST scores. In contrast, Tanaka et $\mathrm{al}^{33}$ demonstrated that a 6-month program of generalized exercise could benefit executive function in older adults with Parkinson's disease. This difference might be due to both subjects (healthy older adults versus older adults with neuropsychiatric disease) and the types of exercise (one-time transient exercise versus 6 months of long-term exercise). The possible mechanisms to explain the effects of moderate exercise often include increased blood flow to the brain, which also brings oxygen and other energy substances acting on the synthesis and metabolism of neurotransmitters, ${ }^{41}$ and induction of brain-derived neurotrophic factor, which maintains brain health and improves neural learning and cognitive function. ${ }^{42}$ However, only a single bout of moderate exercise, such as self-paced walking, does not seem to induce the above beneficial effects.

There were no correlations between salivary $\alpha$-amylase activity and WCST scores. However, positive significant correlations were found between $\triangle \mathrm{sAA}$ and WCST scores

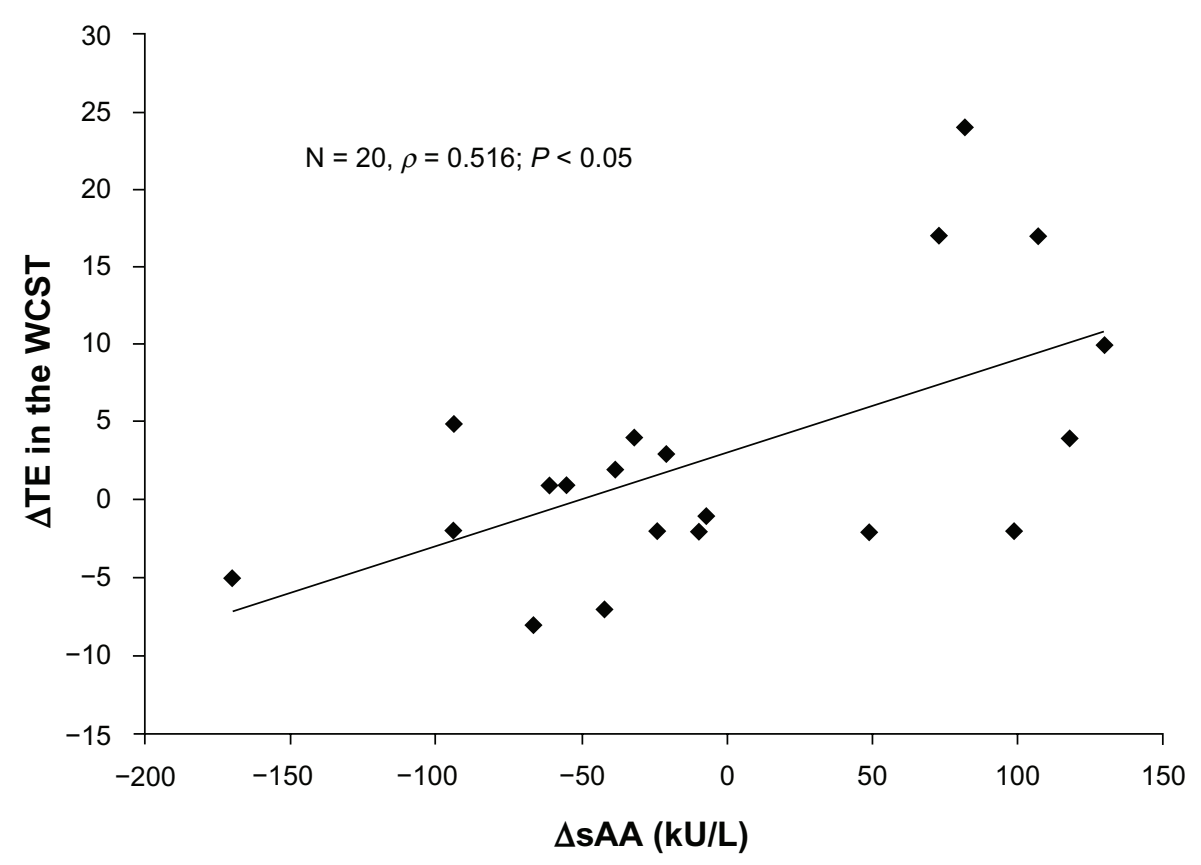

Figure I Scatter plots of the correlations between $\triangle S A A$ and $\triangle T E$ on the WCST.

Notes: A significant correlation between $\Delta \mathrm{sAA}$ and $\Delta \mathrm{TE}$ was found $(\rho=0.516, P<0.05) . \Delta \mathrm{sAA}=$ prewalking and postwalking changes in $\mathrm{sAA}$ activities. $\Delta \mathrm{TE}=$ prewalking and postwalking changes in TE on the WCST.

Abbreviations: sAA, salivary $\alpha$-amylase; TE, total errors; WCST, Wisconsin Card Sorting Test. 


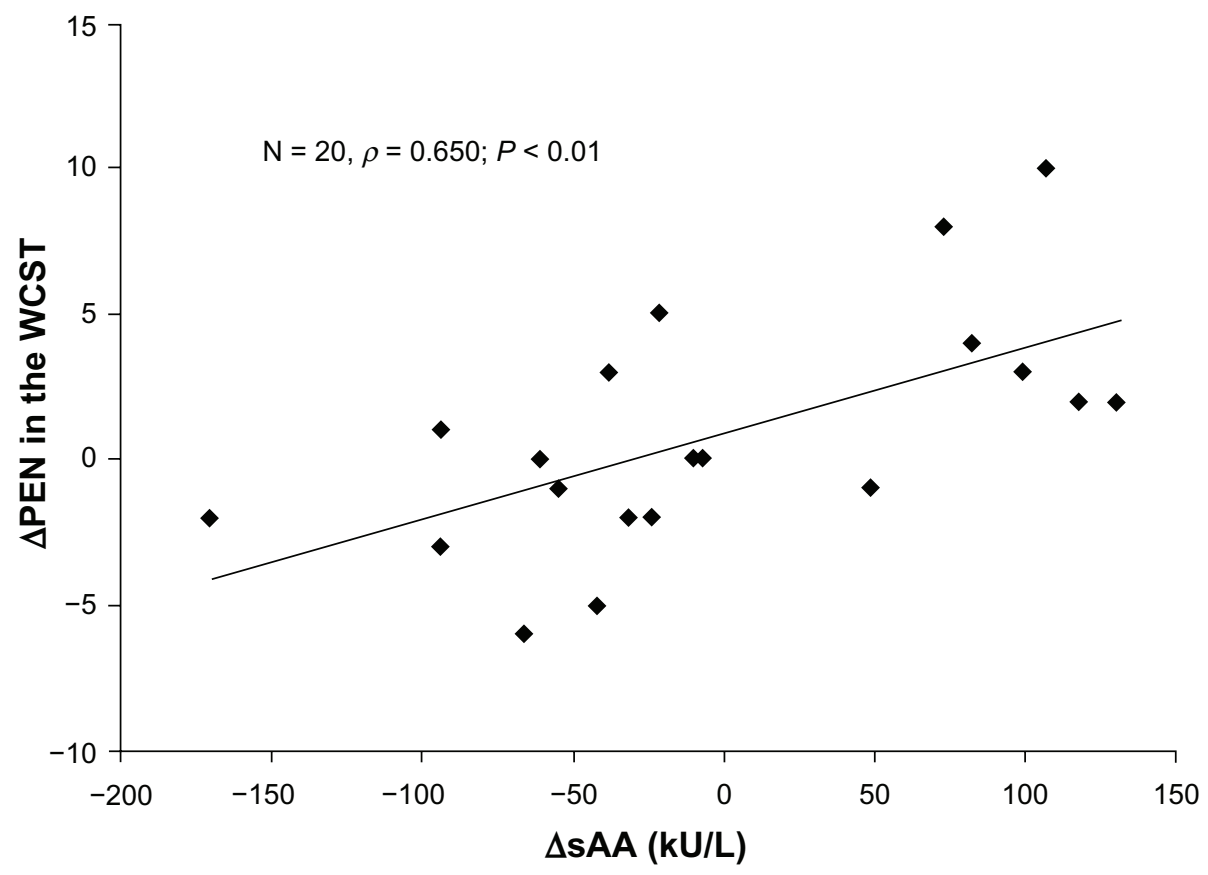

Figure 2 Scatter plots of the correlations between $\triangle$ SAA and $\triangle P E N$ on the WCST.

Notes: A significant correlation $\triangle \mathrm{sAA}$ and $\triangle \mathrm{PEN}$ was found $(\rho=0.650, P<0.0 \mathrm{I}) . \Delta \mathrm{sAA}=$ prewalking and postwalking changes in sAA activities. $\Delta \mathrm{PEN}=$ prewalking and postwalking changes in PEN of the WCST.

Abbreviations: sAA, salivary alpha-amylase; PEN, perseverative errors of Nelson; WCST, Wisconsin Card Sorting Test.

$(\triangle \mathrm{TE}, \triangle \mathrm{PEN})$, suggesting that a significant increase in salivary $\alpha$-amylase activity decreases WCST scores. These correlations indicate that the marked rise in salivary $\alpha$-amylase activity after exercise was accompanied with an increase in the number of total errors and perseverative errors in the WCST. Performance on the WCST depends on multiple processes such as working memory, processing speed, inhibition, and set-shifting. ${ }^{43,44}$ Successful performance in the WCST requires monitoring and use of feedback information, and activity of prefrontal cortex time locked to feedback presentation has been observed in humans performing the WCST. ${ }^{45,46}$ In contrast, inadequate performance on the WCST is considered to be a result of deficits in various cognitive processes, including learning from feedback, maintaining a task goal in mind, noticing that a change in strategy is necessary, inhibiting a previous motor response, switching to a different response, and sustaining a response process over time. ${ }^{47}$ In particular, perseverative errors occur when a participant keeps on sorting the response cards using a previous matching rule after the matching rule has been changed. Slower processing and lower working memory capacity are also linked to perseveration. ${ }^{43,44}$ Gunning-Dixon and $\mathrm{Raz}^{48}$ demonstrated that the volume of the prefrontal cortex and the volume of white matter in the prefrontal region are independently associated with age-related increases in perseverative errors on the WCST. Moreover, Takeda et $\mathrm{al}^{49}$ reported that PEN scores on the WCST mainly reflected regional cerebral blood flow in the right thalamus. Based on the present findings and previous studies, ${ }^{43,44,48,49}$ a significant increase in salivary $\alpha$-amylase activity may temporarily decrease executive function, such as an increase in perseverative errors (ie, a tendency to repeat the same errors or persist in a specific response despite feedback indicating that it is no longer correct).

The present study has several limitations, such as only two measurements of salivary $\alpha$-amylase and a lack of control for use of medication. Future research should measure salivary $\alpha$-amylase more times during exercise, and the duration and intensity of exercise should be controlled. Control for use of medication, sex effects, smoking, and alcohol consumption should be accounted for in a future study. Additionally, this study is lacking a control (nonexercise) group and possible learning effects on WCST cannot be ruled out, so our findings should be further investigated in a controlled, confirmatory study.

In conclusion, it is suggested that a single bout of walking induced beneficial effects on mood in elderly people. These effects are likely to prolong the healthy life expectancy and improve quality of life in elderly adults; however, it is supposed that a significant increase in salivary $\alpha$-amylase activity after walking might temporarily cause a decline in executive function. Elderly adults might need to take 
care to avoid accidents caused by poor concentration or central fatigue after exercise. Further research is needed to examine the associations among actual fitness level, psychophysiologic stress responses, and brain function in elderly people.

\section{Disclosure}

The authors report no conflicts of interest in this work.

\section{References}

1. Sattelmair JR, Pertman JH, Forman DE. Effects of physical activity on cardiovascular and noncardiovascular outcomes in older adults. Clin Geriatr Med. 2009;25(4):677-702.

2. Kaliman P, Párrizas M, Lalanza JF, Camins A, Escorihuela RM, Pallàs M. Neurophysiological and epigenetic effects of physical exercise on the aging process. Ageing Res Rev. 2011;10(4):475-486.

3. Hatta A, Nishihira Y, Kim SR, et al. Effects of habitual moderate exercise on response processing and cognitive processing in older adults. Jpn J Physiol. 2005;55(1):29-36.

4. Hillman CH, Weiss EP, Hagberg JM, Hatfield BD. The relationship of age and cardiovascular fitness to cognitive and motor processes. Psychophysiology. 2002;39(3):303-312.

5. Colcombe SJ, Erickson KI, Raz N, et al. Aerobic fitness reduces brain tissue loss in aging humans. J Gerontol A Biol Sci Med Sci. 2003;58(2) 176-180.

6. Colcombe SJ, Erickson KI, Scalf PE, et al. Aerobic exercise training increases brain volume in aging humans. J Gerontol A Biol Sci Med Sci. 2006;61(11):1166-1170.

7. Forte R, Boreham CA, Leite JC, et al. Enhancing cognitive functioning in the elderly: multicomponent vs resistance training. Clin Interv Aging. 2013;8:19-27.

8. Rhodes MG. Age-related differences in performance on the Wisconsin Card Sorting Test: a meta-analytic review. Psychol Aging. 2004;19(3): 482-494.

9. Cruise KE, Bucks RS, Loftus AM, Newton RU, Pegoraro R, Thomas MG. Exercise and Parkinson's: benefits for cognition and quality of life. Acta Neurol Scand. 2011;123(1):13-19.

10. McEwen BS, Stellar E. Stress and the individual. Mechanisms leading to disease. Arch Intern Med. 1993;153(18):2093-2101.

11. Demirovic D, Rattan SI. Establishing cellular stress response profiles as biomarkers of homeodynamics, health and hormesis. Exp Gerontol. 2013;48(1):94-98.

12. Stupnicki R, Obminski Z. Glucocorticoid response to exercise as measured by serum and salivary cortisol. Eur J Appl Physiol Occup Physiol. 1992;65(6):546-549.

13. O'Connor PJ, Corrigan DL. Influence of short-term cycling on salivary cortisol levels. Med Sci Sports Exerc. 1987;19(3):224-228.

14. Bishop NC, Gleeson M. Acute and chronic effects of exercise on markers of mucosal immunity. Front Biosci. 2009;14:4444-4456.

15. Ljungberg G, Ericson T, Ekblom B, Birkhed D. Saliva and marathon running. Scand J Med Sci Sports. 1997;7(4):214-219.

16. Chatterton RT Jr, Vogelsong KM, Lu YC, Ellman AB, Hudgens GA. Salivary alpha-amylase as a measure of endogenous adrenergic activity. Clin Physiol. 1996;16(4):433-448.

17. Takai N, Yamaguchi M, Aragaki T, Eto K, Uchihashi K, Nishikawa Y. Effect of psychological stress on the salivary cortisol and amylase levels in healthy young adults. Arch Oral Biol. 2004;49(12):963-968.

18. Papacosta E, Nassis GP. Saliva as a tool for monitoring steroid, peptide and immune markers in sport and exercise science. J Sci Med Sport. 2011;14(5):424-434.

19. Rohleder N, Nater UM. Determinants of salivary alpha-amylase in humans and methodological considerations. Psychoneuroendocrinology. 2009;34(4):469-485.
20. Teychenne M, Ball K, Salmon J. Physical activity and likelihood of depression in adults: a review. Prev Med. 2008;46(5):397-411.

21. Fumoto M, Oshima T, Kamiya K, et al. Ventral prefrontal cortex and serotonergic system activation during pedaling exercise induces negative mood improvement and increased alpha band in EEG. Behav Brain Res. 2010;213(1):1-9.

22. Katsura Y, Yoshikawa T, Ueda SY, et al. Effects of aquatic exercise training using water-resistance equipment in elderly. Eur J Appl Physiol. 2010;108(5):957-964.

23. Manor B, Newton E, Abduljalil A, Novak V. The relationship between brain volume and walking outcomes in older adults with and without diabetic peripheral neuropathy. Diabetes Care. 2012;35(9):1907-1912.

24. Vogt T, Schneider S, Brümmer V, Strüder HK. Frontal EEG asymmetry: the effects of sustained walking in the elderly. Neurosci Lett. 2010;485(2):134-137.

25. Winchester J, Dick MB, Gillen D, et al. Walking stabilizes cognitive functioning in Alzheimer's disease (AD) across one year. Arch Gerontol Geriat. 2013;56(1):96-103.

26. Li G, He H. Hormesis, allostatic buffering capacity and physiological mechanism of physical activity: a new theoretic framework. Med Hypotheses. 2009;72(5):527-532.

27. Bassett DR, Schneider PL, Huntington GE. Physical activity in an Old Order Amish community. Med Sci Sports Exerc. 2004;36(1):79-85.

28. Park S, Park H, Togo F, et al. Year-long physical activity and metabolic syndrome in older Japanese adults: cross-sectional data from the Nakanojo Study. J Gerontol A Biol Sci Med Sci. 2008;63(10): 1119-1123.

29. Tudor-Locke C, Craig CL, Aoyagi Y, et al. How many steps/day are enough? For older adults and special populations. Int J Behav Nutr Phys Act. 2011;8:80.

30. Robles TF, Shetty V, Zigler CM, et al. The feasibility of ambulatory biosensor measurement of salivary alpha amylase: relationships with selfreported and naturalistic psychological stress. Biol Psychol. 2011;86(1): $50-56$.

31. Inagaki $\mathrm{T}$, Miyaoka $\mathrm{T}$, Okazaki $\mathrm{S}$, et al. High salivary alphaamylase levels in patients with schizophrenia: a pilot study. Prog Neuropsychopharmacol Biol Psychiatry. 2010;34(4):688-691.

32. Shetty V, Zigler C, Robles TF, Elashoff D, Yamaguchi M. Developmental validation of a point-of-care, salivary $\alpha$-amylase biosensor. Psychoneuroendocrinology. 2011;36(2):193-199.

33. Tanaka K, Quadros AC Jr, Santos RF, Stella F, Gobbi LT, Gobbi S. Benefits of physical exercise on executive functions in older people with Parkinson's disease. Brain Cogn. 2009;69(2):435-441.

34. Schneider S, Askew CD, Diehl J, et al. EEG activity and mood in health orientated runners after different exercise intensities. Physiol Behav. 2009;96(4-5):709-716.

35. Pakkala I, Read S, Leinonen R, Hirvensalo M, Lintunen T, Rantanen $\mathrm{T}$. The effects of physical activity counseling on mood among 75- to 81-year-old people: a randomized controlled trial. Prev Med. 2008;46(5):412-418.

36. Nater UM, Rohleder N. Salivary alpha-amylase as a non-invasive biomarker for the sympathetic nervous system: current state of research. Psychoneuroendocrinology. 2009;34(4):486-496.

37. de Oliveira VN, Bessa A, Lamounier RP, de Santana MG, de Mello MT, Espindola FS. Changes in the salivary biomarkers induced by an effort test. Int J Sports Med. 2010;31(6):377-381.

38. Strahler J, Berndt C, Kirschbaum C, Rohleder N. Aging diurnal rhythms and chronic stress: distinct alteration of diurnal rhythmicity of salivary $\alpha$-amylase and cortisol. Biol Psychol. 2010;84(2):248-256.

39. Hikosaka $O$, Isoda $M$. Switching from automatic to controlled behavior: cortico-basal ganglia mechanisms. Trends Cogn Sci. 2010;14(4): 154-161.

40. Mansouri FA, Matsumoto K, Tanaka K. Prefrontal cell activities related to monkeys' success and failure in adapting to rule changes in a Wisconsin Card Sorting Test analog. J Neurosci. 2006;26(10):2745-2756.

41. Chodzko-Zajko WJ, Moore KA. Physical fitness and cognitive functioning in aging. Exerc Sport Sci Rev. 1994;22:195-220. 
42. Cotman CW, Berchtold NC. Exercise: a behavioral intervention to enhance brain health and plasticity. Trends Neurosci. 2002;25(6): 290-301.

43. Hartman M, Bolton E, Fehnel SE. Accounting for age differences on the Wisconsin Card Sorting Test: decreased working memory, not inflexibility. Psychol Aging. 2001;16(3):385-399.

44. Miyake A, Friedman NP, Emerson MJ, Witzki AH, Howerter A, Wager TD. The unity and diversity of executive functions and their contributions to complex "frontal lobe" tasks: a latent variable analysis. Cogn Psychol. 2000;41(1):49-100.

45. Barceló F. Electrophysiological evidence of two different types of error in the Wisconsin Card Sorting Test. Neuroreport. 1999;10(6): 1299-1303.
46. Monchi O, Petrides M, Petre V, Worsley K, Dagher A. Wisconsin Card Sorting revisited: distinct neural circuits participating in different stages of the task identified by event-related functional magnetic resonance imaging. J Neurosci. 2001;21(19):7733-7741.

47. Geurts HM, Corbett B, Solomon M. The paradox of cognitive flexibility in autism. Trends Cogn Sci. 2009;13(2):74-82.

48. Gunning-Dixon FM, Raz N. Neuroanatomical correlates of selected executive functions in middle-aged and older adults, a prospective MRI study. Neuropsychologia. 2003;41(14):1929-1941.

49. Takeda N, Terada S, Sato S, et al. Wisconsin Card Sorting Test and brain perfusion imaging in early dementia. Dement Geriatr Cogn Disord. 2010;29(1):21-27.

\section{Publish your work in this journal}

Clinical Interventions in Aging is an international, peer-reviewed journal focusing on evidence-based reports on the value or lack thereof of treatments intended to prevent or delay the onset of maladaptive correlates of aging in human beings. This journal is indexed on PubMed Central, MedLine, the American Chemical Society's 'Chemical Abstracts
Service' (CAS), Scopus and the Elsevier Bibliographic databases. The manuscript management system is completely online and includes a very quick and fair peer-review system, which is all easy to use. Visit http://www.dovepress.com/testimonials.php to read real quotes from published authors.

Submit your manuscript here: http://www.dovepress.com/clinical-interventions-in-aging-journal 